\title{
Assistive Technology Devices: A Multidisciplinary Course
}

\author{
Musa Jouaneh, Ying Sun, Robert Comerford \\ University of Rhode Island \\ Kingston, RI 02881
}

\begin{abstract}
This paper reports on a team-based, project-oriented engineering and business course at the University of Rhode Island. The class is a two-semester course sequence that emphasizes invention, innovation and entrepreneurship with focus on the marketing, design, and development of assistive technology devices. Faculty from the Colleges of Engineering and Business Administration guide multi-disciplinary teams through innovative product-oriented design projects in the field of assistive technology. Teams are made up of junior and senior level biomedical engineering, electrical engineering, mechanical engineering and business majors. In the first offering of this course in 2002/2003, a total of 21 students were split into 4 teams. This year, 32 students are split into 5 teams. Teams build prototypes of their designs, prepare business plans, prepare patent applications, and seek commercialization opportunities. The paper discusses course conduct, student assessment, and experiences learned form teaching an interdisciplinary course. This course provides new experiences and capabilities for students that enhance their opportunities of pursuing product design and entrepreneurial activities in their careers.
\end{abstract}

\section{Background}

The assistive technology (AT) industry is characterized by a diversity of AT devices that have limited market potential. Relatively few of them, unlike wheelchairs and hearing aids, have sustainable markets to support mass production and standard business models for consumer products $^{1,2}$. For a majority of AT needs, a question often arises about the technological and financial feasibility of proposed devices. Engineers who develop AT devices should consider both cost-effectiveness, by using off-the-shelf components, and maximizing market potential, by utilizing universal design. A new AT device that does not have sufficient market potential to launch a small business on its own may have to be transferred by licensing, sale or joint venturing to an existing firm that possesses the appropriate manufacturing capability and asset base. Thus, assistive technology presents a unique set of marketing and financial challenges for engineers and business people, not to mention the technical challenges, that demand tight collaboration among them to deliver successful products with short times-to-market.

\footnotetext{
"Proceedings of the 2004 American Society for Engineering Education Annual Conference \& Exposition Copyright (C) 2004, American Society for Engineering Education"
} 
To transfer technology from an academic institution to industry, protection of intellectual property by patents is an important consideration., ${ }^{3,4}$ All manifestations of the course have included AT industry entrepreneur and practitioner guest speakers who provided product operational and patentability evaluations and developmental feedback during various stages in the design process. Further, for the 2002-2003 and 2003-2004 classes, each product team was required to prepare patent applications and present them and their working prototypes to the University of Rhode Island's Intellectual Property Committee (IPC). The IPC evaluates the commercialization prospects as well as technical novelty of each product and, ultimately, decides whether the institution would support continuation of the patenting process and further product development. One of this year's products has been selected for further University support. Many educators have reported on project-based product development courses. Some examples of these include courses developed at Loyola Marymount ${ }^{5}$, Stanford $^{6}$, and University of Virgina ${ }^{7}$.

\section{Project Objectives}

The primary objective of this project is to give participating students hands-on, stimulating exposure to the innovation and entrepreneurial process of business initiation for engineering products with focus on assistive devices. This process includes risk-taking and learning real-world concepts, setting high goals, performing a marketing study, estimating cost and revenue potential, along with design and development of real products prototypes, and business plans for commercialization.

Another objective is to provide training in oral and written presentations and to provide an opportunity for multidisciplinary interaction among team members. This is a new type of outcome that enhances the general direction that engineering education is taking. It is also one of the outcomes specified by ABET, the Accreditation Board for Engineering and Technology. This outcome is a very difficult one for institutions to implement and measure. The third objective is to give an experiential introduction to the necessity for managing the product design process by simultaneous evaluation of design, marketing, financial and production realities, rather than sequential evaluation of them. A final objective is the sensitization of both engineering and business students to the professional orientations of each other. These groups of students would otherwise matriculate and graduate typically with little or no interaction, and consequently would have no appreciation for the other's business perspectives.

\section{Course Conduct}

A two-semester course was developed according to the course outline shown in Table 1. The class met for 1.5 hours per week, for a total of 28 weeks. Each student was expected to spend an additional 3.5 hours per week outside the class. Grading was based on several in-class oral presentations, the prototype, the business plan, and the patent application. Assessment of the course was done by survey forms filled out by the students at the end of the fall semester and the end of the spring semester.

The faculty members brought their expertise on assistive technology, business plan development, and mechanical and electrical design to the class. In addition, eight guest lectures

\footnotetext{
"Proceedings of the 2004 American Society for Engineering Education Annual Conference \& Exposition Copyright (O) 2004, American Society for Engineering Education"
} 
were given by outside experts on assistive technology, intellectual property, manufacturing, small business development, and the AT industry. The guest speakers included four company CEO's. After the multidisciplinary teams were formed, each team identified a specific AT need and technological solution based on interviews with AT users and advice from AT experts. Teams arranged weekly meetings outside the class to carry out the project. Each team was allotted a budget of $\$ 800$ for prototype components. Additional funds for machining customized components and patent search were also available.

\begin{tabular}{|c|c|}
\hline Fall Semester (September-December) & Spring Semester (January-May) \\
\hline $\begin{array}{l}\text { 1. Team forming, identification of an AT } \\
\text { problem } \\
\text { 2. Consultation with AT users and industrial } \\
\text { experts } \\
\text { 3. Product and patent search } \\
\text { 4. Conception of an engineering solution } \\
\text { 5. Market analysis } \\
\text { 6. Proof-of-concept prototype }\end{array}$ & $\begin{array}{l}\text { 7. Intellectual property disclosure } \\
\text { 8. Final prototype } \\
\text { 9. Consultation with experts and } \\
\text { evaluation } \\
\text { 10. Manufacturing and financial plans } \\
\text { 11. Preparation of US patent application } \\
\text { 12. Business plan and commercialization } \\
\text { issues }\end{array}$ \\
\hline
\end{tabular}

\section{Results}

The course was first offered during the 2002-2003 academic year at the University of Rhode Island. A total of 21 students enrolled in this class. These students were seniors from four different disciplines: biomedical engineering, business administration, electrical engineering, and mechanical engineering. Four teams were formed. The four AT devices were all motorized mechanical devices for environmental accommodation.

A self-lowering shelf assembly (Figure 1A) was designed to bring the contents of a wallmounted cabinet outward and to a lower level. A single motor was used to lower the pivotable shelves via two chains on the sides. The novelty of this design was that the motorized shelves are retrofittable to an existing cabinet. A rotating tabletop (Figure 1B) was powered by a low-profile motor under the tabletop. This device was intended for people with limited mobility to access food, frequently used items, or tools by activating a switch. A motorized window opener (Figure 1C) was designed to open double-hung windows. The novelty of this design was its portability. The linear actuator could be quickly and easily moved from one window to another. A motorized reach mechanism (Figure 1D) was designed to be mounted on a wheelchair. The arm could be telescoped inward or outward via a powered screw. A netting mechanism at the tip of the arm was designed to securely capture an object. A servomotor was used to open or close the mouth of the net.

This year (2003/2004) 32 junior and senior students are working on five different projects. Fourteen electrical and biomedical engineering, nine mechanical engineering, and nine business students are enrolled in the class. Current projects include: an automated page-turner

\footnotetext{
"Proceedings of the 2004 American Society for Engineering Education Annual Conference \& Exposition Copyright (C) 2004, American Society for Engineering Education"
} 
which is a single-switch controlled mechanical device that can be used to flip the pages of a book in either direction; a web browser software with a single switch interface for PDAs and computers which allows easy access and navigation of web pages using a single switch interface; a combination of a walker and a powered stander, which performs all the tasks that a normal walker can accomplish, plus aids in standing and sitting motions; an improved manual wheel chair drive system that uses a lever to improve the mechanical advantage of the wheel chair user; and a light activated position sensing array which uses a combination of a light source and a sensor array to provide control signals that can be used to control the movement of a wheel chair or other devices. The automated page-turner has been selected by the University's Intellectual Property Committee for further support by the University.

\section{Students' Feedback}

A questionnaire was given to all the students at the end of the fall and spring semesters of each year to get feedback on this course. The students were asked to rate various course attributes within the following question categories on a scale of zero to 100 :

Performing this project in multidisciplinary teams Collaborating with students from another college Overall rating of the course

The students were told that higher values mean better ratings of these attributes. Table 2 gives a summary of the students' ratings of these items by category. The survey shows that the students liked the opportunity to work in multidisciplinary teams and to collaborate with students from another college as evidenced by the high average score on these items ( 84.5 or higher). Also most students gave a high overall rating for the course (86 average score or higher). Also the data show that there was a slight increase in the average results for two of the above three questions at year-end compared with mid-year. This could be explained by the participating students having a better appreciation of the course team activities at year-end since the majority of the work done in the course is performed in the spring semester. 


\begin{tabular}{|c|c|c|c|c|}
\hline \multicolumn{5}{|c|}{ Table 2. Student's Course Assessment } \\
\hline & & \multicolumn{2}{|c|}{$2002-2003$} & 2003-2004 \\
\hline \multicolumn{2}{|l|}{ Item } & Mid-Year & Year-End & Mid-Year \\
\hline \multirow{4}{*}{$\begin{array}{l}\text { Working in } \\
\text { multidisciplinary } \\
\text { teams }\end{array}$} & Range & $50-100$ & $75-100$ & $70-100$ \\
\hline & Average & 84.5 & 89.5 & 91 \\
\hline & Median & 85 & 90 & 90 \\
\hline & Std. Deviation & 11.5 & 7.7 & 9.3 \\
\hline \multirow{4}{*}{$\begin{array}{l}\text { Collaborating } \\
\text { with students } \\
\text { from another } \\
\text { college }\end{array}$} & Range & $70-100$ & $50-100$ & $50-100$ \\
\hline & Average & 86.6 & 88.9 & 89.9 \\
\hline & Median & 87.5 & 90 & 90 \\
\hline & Std. Deviation & 10.4 & 11.9 & 11.1 \\
\hline \multirow{4}{*}{$\begin{array}{l}\text { Overall rating of } \\
\text { the course }\end{array}$} & Range & $80-100$ & $79-100$ & $65-100$ \\
\hline & Average & 90.2 & 90.1 & 86.0 \\
\hline & Median & 89 & 90 & 85 \\
\hline & Std. Deviation & 6.2 & 6.4 & 9.4 \\
\hline
\end{tabular}

\section{Discussion}

Interdisciplinary problem-based learning projects for assistive technology education have been implemented at other universities in the past ${ }^{8,9}$. In this project we brought business and engineering students together. Market and cost-effectiveness considerations were combined with engineering processes starting from the conception phase and continuing to the completion of prototype development. The one-year course gave each team sufficient time to finish a fully functional prototype, a draft of patent application and business plan. However, the actual patenting process would extend beyond this time frame and would require additional funds. Technology transfer to industry would also require further work on refined prototypes for manufacturing. The course assessment survey generally showed very positive responses from the students. It was a unique course for business and engineering students of different sub-disciplines to collaborate on projects at our university. The students also appreciated learning product development, patent application, and entrepreneurship. 
Figure 1: This figure shows the four AT devices developed by students in 2002-2003: selflowering shelf assembly (A), motorized rotating tabletop (B), portable powered window opener (C), and motorized reach mechanism (D).

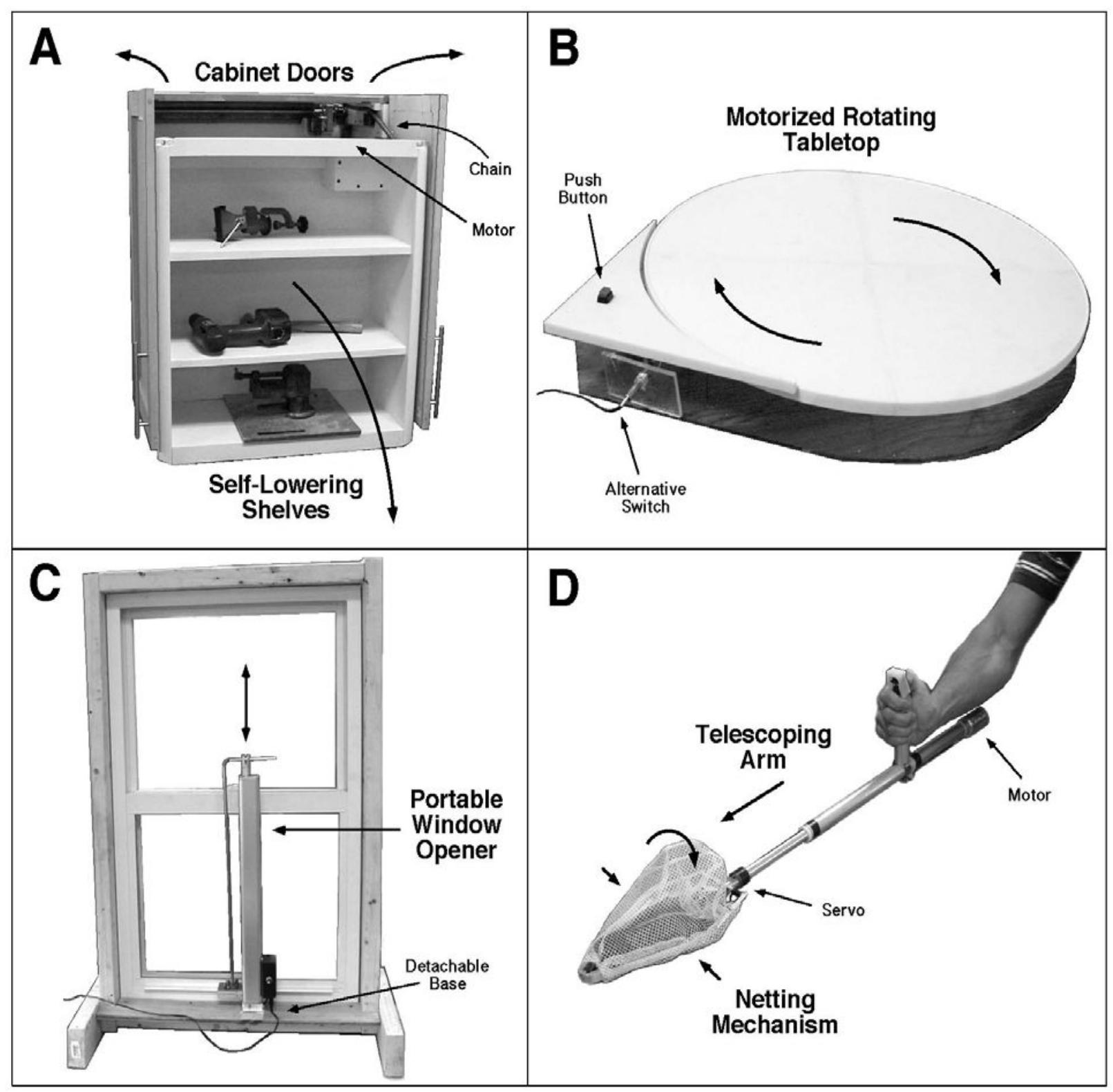

\section{Acknowledgments}

This project was supported by a course development grant from the National Collegiate Inventors and Innovators Alliance (NCIIA). 


\section{References}

1. Andrich R, Ferrario M, Moi M. (1998). A model of cost-outcome analysis for assistive technology. Disabil. Rehabil., 20, 1-24.

2. Oldridge NB. (1996). Outcomes measurement: health state preferences and economic evaluation. Assistive Technology, 8, 94-102.

3. Vernardakis N, Stephanidis C, Akoumianakis D. (1997). Transferring technology toward the European assistive technology industry: Mechanisms and implications. Assistive Technology, 9, 34-46.

4. Berven HM, Blanck PD. (1999). Assistive technology patenting trends and the Americans with Disabilities Act. Behav. Sci. Law, 17, 47-71.

5. Mendelson M. (1997). Integrated product development in the classroom, Proceedings of the 1997 Annual ASEE Conference, Milwaukee, WI, 1-8.

6. Srinivasan V. (2002). Perspective: Ten years of experience teaching a multi-disciplinary product development course. J. Product Innovation Management, 19, 32-45.

7. Mahalik M, Richards L, Gorman M. (1999). Turning students into inventors and entrepreneurs: the continuing evolution of a course on invention and design. Proceedings of the $29^{\text {th }}$ Annual Frontiers in Education Conference, San Juan, PR, 11a6-8-11a6-12.

8. Stern P, Trefler E. (1997). An interdisciplinary problem-based learning project for assistive technology education. Assistive Technology, 9, 152-157.

9. Culver D, Fellows S (1998). Using assistive devices for the disabled to teach design in a freshman engineering course. Proceedings of the 1998 Annual ASEE Conference, Seattle, WA, 1-5.

\section{Biographical Information}

MUSA JOUANEH is professor in the Department of Mechanical Engineering \& Applied Mechanics at the University of Rhode Island. Dr. Jouaneh teaches several courses at URI including Mechanical Systems Design, Assistive Technology Devices, Robotics, and Mechatronics. His research interests include precision machine design, motion control, and high-speed automation. He received his Masters and Doctorate degrees in Mechanical Engineering from the University of California at Berkeley in 1986 and 1989 respectively.

YING SUN is professor of Electrical and Computer Engineering at University of Rhode Island, and the Coordinator of the Biomedical Engineering Program. He teaches courses in Medical Imaging, Biomedical Instrumentation, Computer Communications, and Assistive Technology. His research interests include processing of biomedical imagery, modeling of cardiovascular system, computer vision, and instrumentation for neurophysiology.

ROBERT COMERFORD is professor of management at the College of Business Administration, University of Rhode Island, where he has taught entrepreneurship, small business management, and strategic management since 1975. His research has focused on the economics and financial structure of marine-related businesses. He is the author of Strategic Management: Text, Tools and Cases for Business Policy (with Dennis Callaghan), Kent/Wadsworth Publishing Co., Boston, 1985. 